\title{
Matéria
}

ISSN 1517-7076

Revista Matéria, v. 13, n. 3, pp. 418 - 428, 2008

http://www.materia.coppe.ufrj.br/sarra/artigos/artigo11032

\section{Eletrorrecuperação de cobre e oxidação de cianeto de efluentes cianídricos diluídos gerados por unidade de galvanoplastia}

\author{
Pombo, F.R.'; Dutra, A.J.B. ${ }^{\mathrm{I}}$ \\ ${ }^{\text {I }}$ PEMM/COPPE-UFRJ - Caixa postal: 68505 - CEP: 21941-972 - Rio de Janeiro, RJ. \\ e-mail: pombo@metalmat.ufrj.br, adutra@metalmat.ufrj.br
}

\section{RESUMO}

Apesar de sua elevada toxicidade, eletrólitos cianídricos são amplamente empregados pelas indústrias de eletrorrecobrimento devido à qualidade dos depósitos metálicos obtidos. Na Casa da Moeda do Brasil, o processo de eletrodeposição de cobre sobre aço carbono é utilizado para a fabricação das moedas de um e cinco centavos, gerando, ao seu final, dois tipos de efluentes: um concentrado, após a sangria de eletrólitos contaminados; e outro diluído, após a lavagem dos discos eletrorrevestidos de cobre. Em um trabalho anterior, avaliou-se a possibilidade de se recuperar eletroliticamente o cobre e oxidar parte do cianeto existente nos efluentes concentrados, alcançando-se bons resultados para os teores finais de cobre e cianeto livre partindo-se de uma solução contendo $26 \mathrm{~g} / \mathrm{L}$ de cobre e $27 \mathrm{~g} / \mathrm{L}$ de cianeto total. O presente trabalho visou testar em escala de bancada uma célula eletrolítica para o tratamento dos efluentes diluídos, partindo-se de uma solução sintética contendo $200 \mathrm{mg} / \mathrm{L}$ de cobre e $130 \mathrm{mg} / \mathrm{L}$ de cianeto livre. Nas condições de vazão de $0,37 \mathrm{~mL} / \mathrm{s}$ e a $50^{\circ} \mathrm{C}$, alcançou-se concentrações finais de $0,7 \mathrm{mg} / \mathrm{L}$ de cobre e $0,08 \mathrm{mg} / \mathrm{L}$ de cianeto livre para uma corrente elétrica de $1,5 \mathrm{~A}$, e menor que $0,5 \mathrm{mg} / \mathrm{L}$ de cobre e $0,08 \mathrm{mg} / \mathrm{L}$ de cianeto livre para uma corrente elétrica de 2A, após três horas de eletrólise.

Palavras-chaves: cobre, cianeto, eletrorrecuperação, efluente.

\section{Copper electrowinning and cyanide oxidation from diluted cyanide wastewaters generated by an electroplating plant}

\section{ABSTRACT}

Despite their high toxicity, cyanide electrolytes are widely used by metal finishing industries due to the quality of metallic deposits obtained. At the Brazilian Mint, the process of copper electroplating onto carbon steel is used to make coins of one and five cents, generating, at the end, two types of wastewaters: one concentrated, after bleeding the contaminated electrolytes; and another diluted, after washing the disks electroplated with copper. In a previous work the possibility of electrolytically recovering copper and oxidizing part of the existing cyanide in the concentrated effluents was evaluated, reaching good results for the final concentration of copper and free cyanide starting with a solution containing $26 \mathrm{~g} / \mathrm{L}$ of copper and $27 \mathrm{~g} / \mathrm{L}$ of total cyanide. The present work aimed at testing in a bench scale an electrolytic cell for the treatment of diluted effluents, starting from a synthetic solution containing $200 \mathrm{mg} / \mathrm{L}$ of copper and $130 \mathrm{mg} / \mathrm{L}$ of free cyanide. Under flow conditions of $0.37 \mathrm{~mL} / \mathrm{s}$ at $50^{\circ} \mathrm{C}$, the final concentrations of $0.7 \mathrm{mg} / \mathrm{L}$ for copper and $0.08 \mathrm{mg} / \mathrm{L}$ for free cyanide were obtained for an electric current of $1.5 \mathrm{~A}$, and less than $0.5 \mathrm{mg} / \mathrm{L}$ for copper and $0.08 \mathrm{mg} / \mathrm{L}$ for free cyanide were obtained for an electric current of $2 \mathrm{~A}$, after three hours of electrolysis.

Keywords: copper, cyanide, electrowinning, effluent.

\section{INTRODUÇÃO}

As usinas de processamento de minérios auríferos e as indústrias de galvanoplastia utilizam o cianeto como reagente em seus processos, no primeiro caso como agente lixiviante e no segundo, como constituinte do eletrólito [1, 2], devido a uma série de benefícios a tais procedimentos industriais, apesar da elevada toxicidade do cianeto [3]. Portanto, tais procedimentos industriais geram significativas quantidades de efluente industrial contendo cianeto e metais pesados em solução, os quais devem ser tratados, tanto por 
motivos econômicos (reciclagem de reagentes e recuperação de metais) como por questões ambientais (minimização de impactos ambientais).

Na Casa da Moeda do Brasil, o processo de eletrodeposição de cobre é usado na fabricação de moedas de um e cinco centavos a partir de um banho contendo 25-27g/L de cobre, 12-14g/L de KOH, [4-6] g/L de KCN, 2,5\% (Vol.) de abrilhantador e até 350g/L de $\mathrm{K}_{2} \mathrm{CO}_{3}$. Quando o teor de carbonato de potássio ultrapassa o limite estabelecido, parte do banho é descartado dando origem a um efluente concentrado, enquanto que um efluente diluído contendo centenas de miligramas por litro de cobre e cianeto livre é gerado após a lavagem das peças (moedas) eletrorrecobertas de cobre.

No Brasil, o Conselho Nacional do Meio Ambiente, em sua Resolução no 357 de 17 de março de 2005, fixou os padrões para descarte de efluentes nos corpos receptores, estabelecendo, para os teores finais de cobre e cianeto total, 1,0 mg/L e 0,2 mg/L, respectivamente. Entretanto, o método comumente empregado pelas indústrias de acabamento metálico para tratar seus efluentes (precipitação química com hidróxidos e sulfetos) não é satisfatório do ponto de vista ambiental [7], resultando numa geração de grande quantidade de lamas tóxicas (hidróxidos e sulfetos metálicos), que são resíduos sólidos perigosos e classificados como classe I, segundo a ABNT [8].

Existe, na literatura, a descrição de uma série de métodos para tratar efluentes contendo cianeto, com o objetivo de sua degradação ou de sua reciclagem [9, 10], que devem ser realizados junto com a precipitação química para a remoção metálica. Os que têm por finalidade a degradação de cianeto utilizam, em geral, oxidantes tais como peróxido de hidrogênio e hipoclorito de sódio, gerando, ao final do processo, lamas tóxicas; já aqueles que têm por finalidade a reciclagem de cianeto geram, em geral, soluções concentradas, que se não puderem ser aproveitadas se tornarão um outro passivo ambiental.

Os processos eletrolíticos propiciam a recuperação dos metais numa forma pura, sem a geração de resíduos [11] e com a oxidação simultânea do cianeto livre, conforme mostrado nas reações abaixo. A Reação 1 representa a redução de cobre a partir de seu complexo, a reação 2 mostra a oxidação de cianeto livre formando um composto gasoso intermediário conhecido como cianogênio [12, 13], o qual sofre hidrólise formando cianato [Reação 3].

Reação catódica:

Reações anódicas:

$$
2 \mathrm{CN}^{-} \leftrightarrow(\mathrm{CN})_{2}+2 \mathrm{e}^{-}
$$

$$
(\mathrm{CN})_{2}+2 \mathrm{OH}^{-} \rightarrow \mathrm{OCN}^{-}+\mathrm{CN}^{-}+\mathrm{H}_{2} \mathrm{O}
$$

Em soluções cianídricas contendo cobre, três espécies complexas podem estar presentes: $\mathrm{Cu}(\mathrm{CN})_{2}{ }^{-}$, $\mathrm{Cu}(\mathrm{CN})_{3}{ }^{2-}$ e $\mathrm{Cu}(\mathrm{CN})_{4}{ }^{3-}$. A Tabela 1 apresenta as energias livres e os potenciais de eletrodo padrão para as reações de redução dos três complexos mencionados [13].

Tabela 1: Energias livres e potenciais de eletrodo padrão para as reações possíveis envolvendo a redução de cobre em meio cianídrico [13].

\begin{tabular}{|c|c|c|}
\hline Reação & $\left.\Delta \mathbf{G}^{\mathbf{0}} \mathbf{( \mathbf { k J ~ m o l }} \mathbf{~}^{\mathbf{1}}\right)$ & $\mathbf{E}^{\mathbf{0}} \mathbf{( \mathbf { V } )}$ \\
\hline $\mathrm{Cu}(\mathrm{CN})_{2}{ }^{-}+\mathrm{e}^{-} \rightarrow \mathrm{Cu}+2 \mathrm{CN}$ & 42,80 & $-0,444$ \\
\hline $\mathrm{Cu}(\mathrm{CN})_{3}{ }^{2-}+\mathrm{e}^{-} \rightarrow \mathrm{Cu}+3 \mathrm{CN}$ & 116,2 & $-1,205$ \\
\hline $\mathrm{Cu}(\mathrm{CN})_{4}{ }^{3-}+\mathrm{e}^{-} \rightarrow \mathrm{Cu}+4 \mathrm{CN}$ & 124,6 & $-1,292$ \\
\hline
\end{tabular}

Reportou-se na literatura $[12,14]$ que a pısença de cobre catalisa a reação de oxidação de cianeto livre através da formação de um filme anódico de óxidos de $\mathrm{Cu}(\mathrm{I})$ e $\mathrm{Cu}(\mathrm{II})$. Um aumento de temperatura também resulta numa maior taxa da reação de oxidação de cianeto [15], além de sugerir um aumento do potencial de redução do par $\mathrm{Cu}(\mathrm{I}) / \mathrm{Cu}$ através da diminuição das constantes termodinâmicas de formação global dos ciano-complexos de cobre [1].

A concentração dos efluentes industriais é um fator chave para a recuperação de metais com objetivos de sua venda ou reúso. Um efluente que foi concentrado, ou pelo menos não diluído, é freqüentemente mais econômico e mais fácil de ser tratado que aqueles dispersos em grandes quantidades de água. Conseqüentemente, os diferentes tipos de efluentes de galvanoplastia, tais como aqueles gerados pela 
sangria do eletrólito (efluentes concentrados) e aqueles gerados pela lavagem das peças após o processo de eletrodeposição (efluentes diluídos) não devem ser misturados.

O uso de processos eletrolíticos como uma alternativa para oxidação de cianeto com a simultânea recuperação de cobre e metais preciosos a partir de soluções diluídas foi investigada por alguns pesquisadores $[2,4,6,14,15]$. Eles usaram eletrodos com elevada área superficial, como carbono vítreo reticulado ou feltro de carbono para a remoção de metais de soluções com concentrações menores que $1 \mathrm{~g} / \mathrm{L}$ de cobre ou na faixa de 5 a $30 \mathrm{mg} / \mathrm{L}$ para ouro e prata. Embora estes eletrodos porosos sejam eficientes para o tratamento de soluções diluídas, para o tratamento de soluções concentradas, o rápido entupimento dos poros, devido à intensa deposição metálica, surge como um problema a ser contornado. Além disso, sua durabilidade em soluções alcalinas ainda é uma incógnita. Nesse caso, outro tipo de eletrodo deveria ser empregado [16].

O objetivo deste trabalho foi desenvolver e testar em escala de bancada uma célula eletrolítica com catodo na forma de tela aço inoxidável AISI 304 dobrada e anodos de titânio revestido com óxido de rutênio, para a recuperação do cobre e oxidação de cianeto livre de efluentes aquosos diluídos contendo cianeto, evitando assim o descarte de efluentes altamente tóxicos no meio ambiente. O efluente foi preparado em laboratório, simulando aquele gerado após a lavagem das moedas eletrorrevestidas de cobre na Casa da Moeda do Brasil. A meta almejada foi adequar os padrões de cobre e cianeto total àqueles estipulados pelo CONAMA.

\section{MATERIAIS E MÉTODOS}

\subsection{Testes voltamétricos}

Foram realizados testes voltamétricos, empregando-se um potenciostato/galvanostato EG\&G Princeton Applied Research molelo 273-A, tendo como interface o cartão controlador GPIB STD-8410 e aquisição de dados pelo programa Research Electrochemistry Software 4.00, modelo 270/250 da EG\&G Instruments. A célula de vidro empregada nas voltametrias era composta de duas partes, sendo que uma continha o capilar de Luggin e nela encontrava-se o eletrodo de referência de calomelano saturado (ECS). Na outra parte, encontravam-se o eletrodo de trabalho, o borbulhador de nitrogênio e o contra-eletrodo. Os eletrodos de trabalho foram um disco rotatório de aço inoxidável com $1,0 \mathrm{~cm}^{2}$ de área, nos ensaios catódicos, e um disco de titânio revestido com óxido de rutênio com $0,55 \mathrm{~cm}^{2}$ de área, nos ensaios anódicos. Como contra-eletrodo foi utilizado um fio de platina. Antes de cada teste voltamétrico purgou-se a solução com nitrogênio durante cerca de 40 minutos, com o objetivo de remover o oxigênio dissolvido. As soluções testadas possuíam $200 \mathrm{mg} / \mathrm{L}$ de cobre e $130 \mathrm{mg} / \mathrm{L}$ de cianeto livre, e foram preparadas com reagentes de grau analítico $\left(\mathrm{K}_{2} \mathrm{SO}_{4}, \mathrm{NaOH}, \mathrm{NaCN}\right.$ e $\left.\mathrm{CuCN}\right)$.

\subsection{Sistema de eletrorrecuperação de cobre}

Nos ensaios para a recuperação de cobre e oxidação de cianeto livre utilizou-se uma célula de acrílico de compartimento único, por onde o eletrólito passava paralelamente aos eletrodos porosos, ou seja, a vazão do eletrólito possuía direção perpendicular à corrente aplicada. Na célula eletrolítica, utilizaram-se dois anodos e um catodo. Os anodos consistiram em telas de titânio revestidas com óxido de rutênio $\left(\mathrm{RuO}_{2}\right)$, com dimensões de $25 \mathrm{~cm}$ por $5 \mathrm{~cm}$, e como catodo foi utilizado uma tela de aço inoxidável, dobrada em 10 vezes de modo a aumentar a área catódica, resultando em uma área igual a $599,8 \mathrm{~cm}^{2}$. A célula eletrolítica, de volume igual a aproximadamente $120 \mathrm{~mL}$, foi alimentada por reservatório com um litro de solução. A concentração de cobre foi monitorada pela técnica de absorção atômica, utilizando-se um espectrofotômetro modelo AA 6800 da Shimadzu, e a massa final de cobre recuperada também foi verificada pela pesagem dos catodos antes e depois o processo de eletrodeposição. A concentração de cianeto livre foi monitorada pela técnica de titulação com nitrato de prata, com a utilização de hidróxido de amônio para ajuste de pH e de iodeto de potássio como indicador.

A Figura 1 apresenta o esquema da montagem experimental utilizado nos testes voltamétricos (A) e nos testes de eletrorrecuperação de cobre (B). 


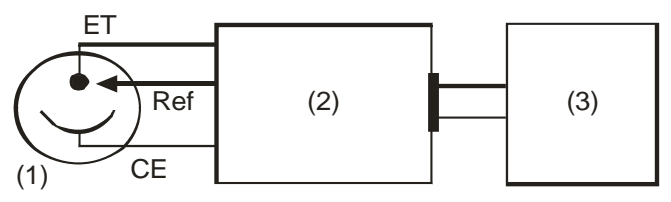

(1) Célula eletroquímica

(2) Potenciostato

(3) Computador

ET: Eletrodo de trabalho

Ref: Eletrodo de referência

CE: Contra-eletrodo

\section{(A)}

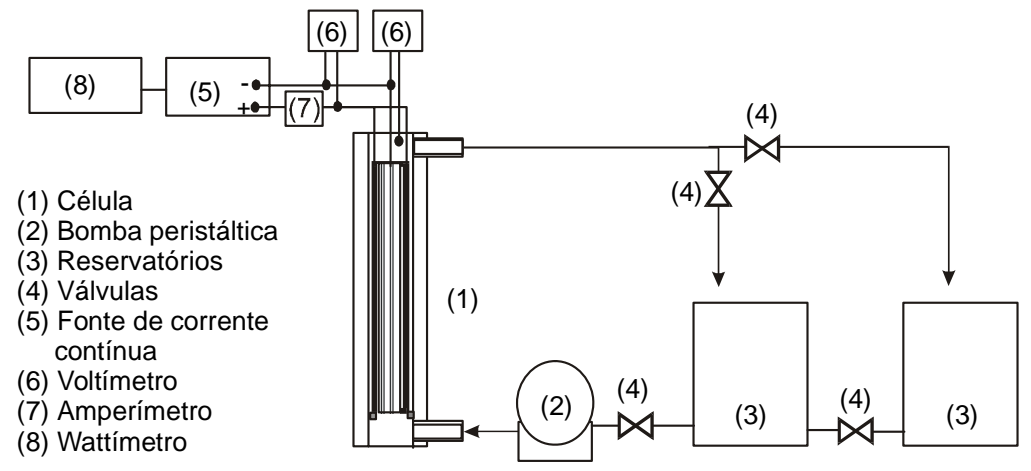

(B)

Figura 1: Esquema das aparelhagens experimentais utilizadas nos testes voltamétricos (A) e nos testes de eletrorrecuperação de cobre (B).

\section{RESULTADOS E DISCUSSÃO}

\subsection{Testes voltamétricos}

As voltametrias tiveram como objetivo definir os parâmetros ideais para os ensaios de recuperação eletrolítica de cobre do efluente sintético em estudo. A Figura 2 apresenta a influência da velocidade de rotação do eletrodo nas curvas de polarização catódica. Nota-se que o aumento da velocidade de rotação conduz a um aumento da altura do plateau de densidade de corrente limite em cerca de $-1300 \mathrm{mV}$, devido a uma diminuição da espessura da camada limite. Isso sugere que um aumento de vazão nos ensaios na célula eletrolítica de bancada resultaria em um aumento da eficiência de corrente catódica, ocorrendo uma melhoria do processo de eletrorrecuperação de cobre.

A Figura 3 apresenta duas curvas de polarização catódica, realizadas a 25 e a $50^{\circ} \mathrm{C}$, mostrando que o aumento de temperatura facilita a deposição de cobre a partir de seus complexos. Isso ocorre devido a um deslocamento na predominância dos complexos em direção àqueles de menor número de coordenação [1], causando um aumento do potencial de equilíbrio da reação de redução $(\operatorname{par} \mathrm{Cu}(\mathrm{I}) / \mathrm{Cu})$. Como conseqüência a deposição de cobre inicia-se em potenciais menos catódicos para a temperatura mais elevada. Além disso, na medida em que aumentamos a temperatura, aumentamos também a altura do plateau de densidade de corrente limite, ocorrendo, portanto, um aproveitamento maior da corrente catódica para a redução do $\mathrm{Cu}(\mathrm{I})$, implicando numa elevação da eficiência de corrente. 


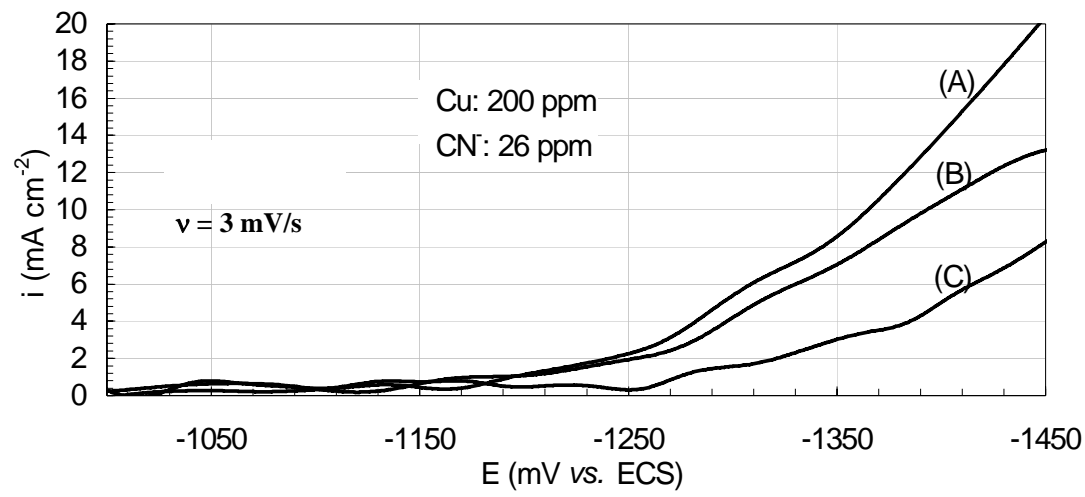

Figura 2: Influência da velocidade de rotação do eletrodo nas curvas de polarização catódica, para soluções contendo $0,2 \mathrm{~mol} / \mathrm{L}$ de $\mathrm{K}_{2} \mathrm{SO}_{4}, 10^{-3} \mathrm{~mol} / \mathrm{L}$ de $\mathrm{NaOH}, 10^{-3} \mathrm{~mol} / \mathrm{L}$ de $\mathrm{CN}^{-}$como NaCN e 3,15 x $10^{-3} \mathrm{~mol} / \mathrm{L}$ de Cu como CuCN, efetuadas com um eletrodo de disco rotatório de aço inoxidável com 1,0 $\mathrm{cm}^{2}$ de área. (A) 1700 rpm; (B) 1500 rpm; e (C) 1300 rpm.

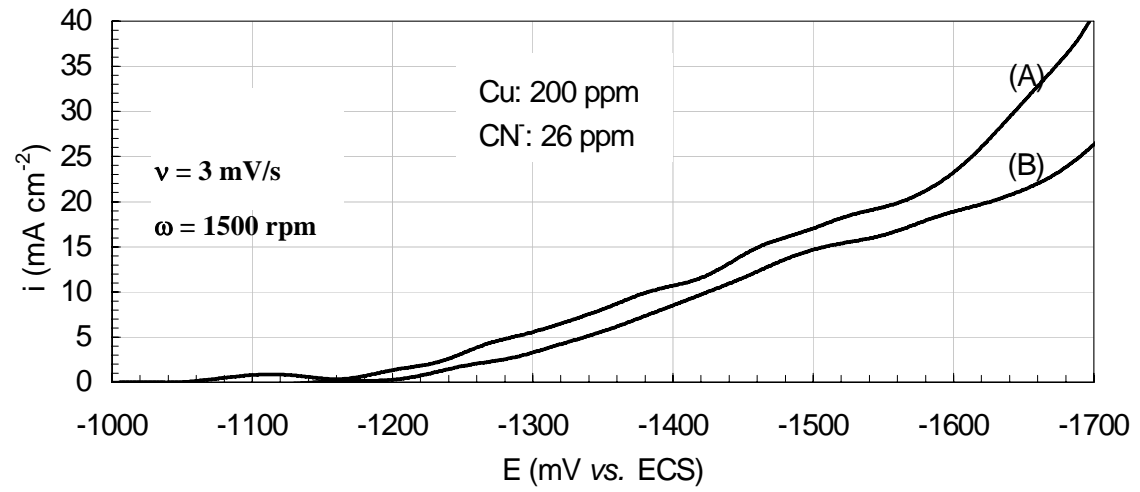

Figura 3: Influência da temperatura nas curvas de polarização catódica, para soluções contendo 0,2 mol/L de

$\mathrm{K}_{2} \mathrm{SO}_{4}, 10^{-3} \mathrm{~mol} / \mathrm{L}$ de $\mathrm{NaOH}, 10^{-3} \mathrm{~mol} / \mathrm{L}$ de $\mathrm{CN}^{-}$como NaCN e $3,15 \times 10^{-3} \mathrm{~mol} / \mathrm{L}$ de $\mathrm{Cu}$ como CuCN, efetuadas com um eletrodo de disco rotatório de aço inoxidável com $1,0 \mathrm{~cm}^{2}$ de área. (A) $50^{\circ} \mathrm{C}$ e (B) $25^{\circ} \mathrm{C}$.

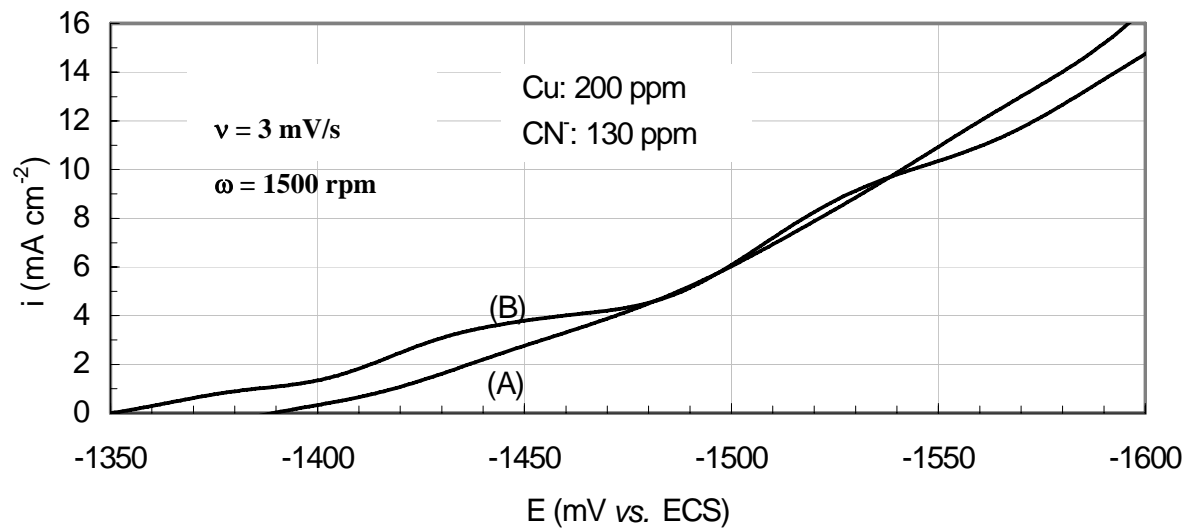

Figura 4: Voltametrias de varredura linear catódica, para soluções contendo $0,2 \mathrm{~mol} / \mathrm{L}$ de $\mathrm{K}_{2} \mathrm{SO}_{4}, 10^{-3} \mathrm{~mol} / \mathrm{L}$ de $\mathrm{NaOH}$ e $5 \times 10^{-3} \mathrm{~mol} / \mathrm{L}$ de $\mathrm{CN}^{-}$como $\mathrm{NaCN}$, efetuadas com um eletrodo de disco rotatório de aço inoxidável com 1,0 $\mathrm{cm}^{2}$ de área. (A) sem cobre e (B) com 3,15 x 10 $0^{-3} \mathrm{~mol} / \mathrm{L}$ de Cu como CuCN.

Uma voltametria de varredura linear catódica foi realizada com o objetivo de estudar os potenciais de deposição do cobre a partir de seus complexos, para as concentrações utilizadas na célula eletrolítica. A partir do voltamograma mencionado (Figura 4B), nota-se que, nessas condições, a deposição do cobre, a partir do complexo $\mathrm{Cu}(\mathrm{CN})_{3}{ }^{2-}$, inicia-se em um potencial ligeiramente inferior a $-1350 \mathrm{mV}$, alcançando um plateau de densidade de corrente limite em torno de $-1380 \mathrm{mV}$. E a deposição do cobre, a partir do complexo $\mathrm{Cu}(\mathrm{CN})_{4}{ }^{3-}$, começa em um potencial igual a aproximadamente $-1400 \mathrm{mV}$, alcançando um plateau de densidade de corrente limite em torno de $-1450 \mathrm{mV}$. 
Após um potencial de cerca de $-1490 \mathrm{mV}$, o acréscimo de corrente está associado a uma intensa geração de hidrogênio, fato confirmado com a superposição da voltametria da Figura 4B com outra realizada com a mesma concentração de cianeto livre, porém sem o cobre (Figura 4A).

\subsection{Testes de recuperação de cobre}

A temperatura apresenta influência muito marcante na remoção de cobre a partir de soluções cianídricas diluídas, como pode ser observado na Figura 5. Essa melhoria considerável na recuperação eletrolítica de cobre com o aumento da temperatura deve-se ao aumento do potencial de deposição do par $\mathrm{Cu}$ (I)/Cu como mostrou a Figura 3 e ao aumento da mobilidade das espécies eletroativas, sendo que o último leva a um aumento da condutividade da solução ao aumento da altura do plateau de densidade de corrente limite.

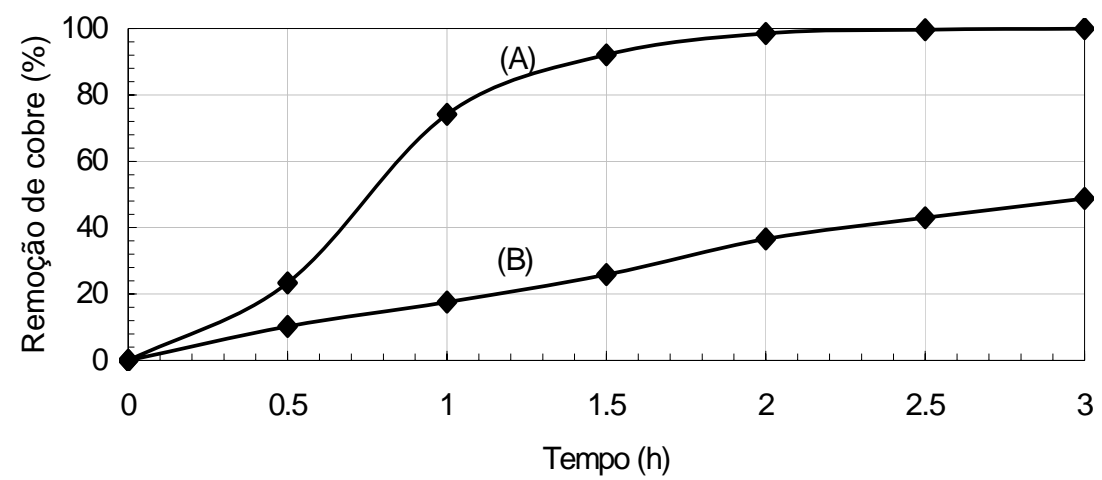

Figura 5: Influência da temperatura nas taxas de remoção de cobre, para soluções contendo 0,2 mol/L de $\mathrm{K}_{2} \mathrm{SO}_{4}, 10^{-2} \mathrm{~mol} / \mathrm{L}$ de $\mathrm{NaOH}, 5 \times 10^{-3} \mathrm{~mol} / \mathrm{L}$ de $\mathrm{CN}^{-}$como NaCN e 3,15 x $10^{-3} \mathrm{~mol} / \mathrm{L}$ de Cu como CuCN, nas seguintes condições: corrente elétrica de $2 \mathrm{~A}$ e vazão de $0,37 \mathrm{~mL} / \mathrm{s}$. (A) $50^{\circ} \mathrm{C}$ e (B) $25^{\circ} \mathrm{C}$.

A influência da vazão da solução na eletrodeposição de cobre nos testes eletrolíticos foi verificada, concluindo-se que o aumento da mesma contribui para a elevação da taxa de remoção de cobre, porém à custa do aumento do consumo energético do processo, devido à ocorrência de um maior potencial da célula eletrolítica. Tal aumento de potencial pode estar associado ao aumento da turbulência entre os eletrodos, causado pela geração mais intensa de gases (hidrogênio no catodo e oxigênio no anodo) e pelo aumento da taxa de geração de $\mathrm{CN}^{-}$na superfície do catodo, ocasionada pela maior taxa de remoção de cobre e causando uma maior polarização do mesmo.

Partindo-se da equação geral para a conversão fracional (fração da quantidade inicial de reagente removida no tempo $t$ ) e da equação para a conversão fracional de um reator de fluxo pistonado em batelada com reciclo [17], modelo que se adéqua ao projeto da célula eletrolítica utilizada, uma análise da validade do mesmo pôde ser verificada, cabendo mencionar que tal modelagem assume que o processo eletroquímico possui controle completo por transporte de massa. Igualando-se as equações, tem-se que (Equação 4):

$$
X_{A, t}=1-\frac{c(t)}{c(0)}=1-\exp \left\{\frac{-t}{\tau}\left[1-\exp \left(\frac{-k_{m} A}{Q}\right)\right]\right\}
$$

onde, $\mathrm{X}_{\mathrm{A}, \mathrm{t}}$ é a fração convertida para um eletrodo de área A no tempo t, c(t) a concentração de cobre no tempo $\mathrm{t}, \mathrm{c}(0)$ a concentração de cobre no tempo $\mathrm{t}=0, \mathrm{~km}$ o coeficiente de transporte de massa médio, $\mathrm{V} o$ volume do reator, $Q$ a vazão volumétrica e $\tau$ o tempo de residência $(\tau=V / Q)$.

Multiplicando-se por (-1) e aplicando-se logaritmo dos dois lados, obtêm-se a Equação 5:

$$
\ln \left(\frac{c(t)}{c(0)}\right)=\frac{-t}{\tau}\left[1-\exp \left(\frac{-k_{m} A}{Q}\right)\right]
$$

Logo, chega-se ao resultado apresentado na Equação 6: 


$$
-\ln \left(\frac{c(t)}{c(0)}\right)=t \cdot\left(\frac{d}{\tau}\right)
$$

onde, d é uma constante e equivale a $1-\exp \left(\frac{-k_{m} A}{Q}\right)$.

Analisando-se a Equação 6, conclui-se que um gráfico de - $\ln (c(t) / c(0))$ em função do tempo teria que resultar em uma reta passando na origem (coeficiente linear igual a 0), caso o processo, num reator de fluxo pistonado, seja controlado por transporte de massa. A Figura 6 apresenta o gráfico de $-\ln (\mathrm{c}(\mathrm{t}) / \mathrm{c}(0))$ versus tempo para o teste apresentado na Figura 5B. Como pode ser observado, tal gráfico resulta numa reta passando na origem, comprovando que o processo eletroquímico que ocorre no presente trabalho possui controle por transporte de massa. Ainda, o valor de $\mathrm{k}_{\mathrm{m}}$ pôde ser calculado a partir da Equação 6 , sendo igual a $1,23 \times 10^{-5} \mathrm{~cm} / \mathrm{s}$.

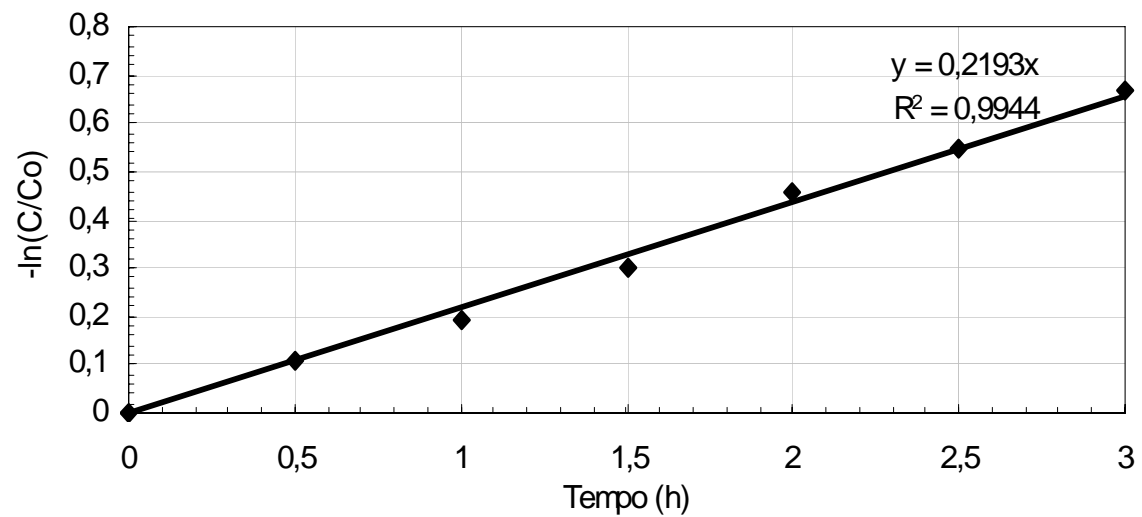

Figura 6: Variação de $-\ln (c(t) / c(0))$ em função do tempo, utilizando os dados do teste apresentado na curva $5 B$.

Ensaios com a temperatura de $50^{\circ} \mathrm{C}$ e com uma vazão de $0,50 \mathrm{~mL} / \mathrm{s}$ foram realizados, variando-se a corrente. Esses resultados estão representados pela Figura 7. Neste caso, para uma corrente de 2A, as concentrações de cobre e cianeto livre foram, respectivamente, $0,6 \mathrm{mg} / \mathrm{L}$ e $0,14 \mathrm{mg} / \mathrm{L}$, com um consumo específico de $82,52 \mathrm{kWh} / \mathrm{kg}$ e, para uma corrente de $3 \mathrm{~A}$, menor que 0,5 mg/L e 0,07 mg/L, com um consumo energético específico de 134,36 kWh/kg. Nota-se, na Figura 7, o aumento gradativo da taxa de remoção de cobre na primeira hora de eletrólise (aumento da derivada das curvas) e que se deve ao fato de ser mais fácil depositar cobre sobre o próprio cobre, ao invés de sobre aço inox, pois a superfície do depósito é rugosa, aumentando a área do catodo; e após uma hora de eletrólise, a diminuição da concentração de cobre em solução passa a ser o fator limitante, ocorrendo, conseqüentemente, a diminuição da taxa de recuperação de cobre.

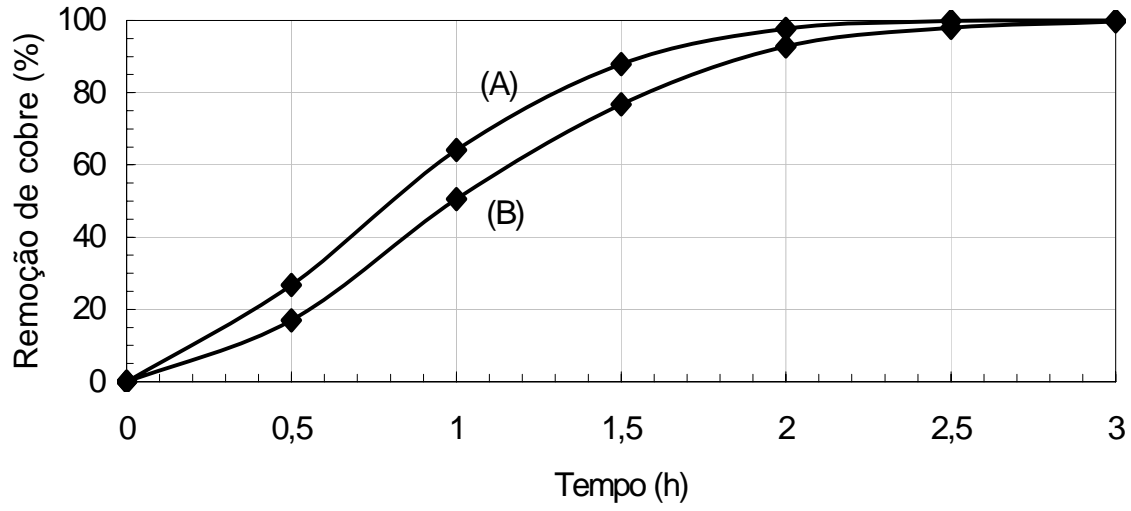

Figura 7: Influência da corrente nas taxas de remoção de cobre, para soluções contendo 0,2 mol/L de $\mathrm{K}_{2} \mathrm{SO}_{4}$, $10^{-2} \mathrm{~mol} / \mathrm{L}$ de $\mathrm{NaOH}, 5 \times 10^{-3} \mathrm{~mol} / \mathrm{L}$ de $\mathrm{CN}^{-}$como NaCN e 3,15 x $10^{-3} \mathrm{~mol} / \mathrm{L}$ de Cu como CuCN, nas seguintes condições: $50^{\circ} \mathrm{C}$ e vazão de $0,50 \mathrm{~mL} / \mathrm{s}$. (A) $3 \mathrm{~A}$ e (B) $2 \mathrm{~A}$. 
Testes com uma vazão menor foram realizados com o objetivo de alcançarem-se consumos energéticos específicos mais baixos que os anteriores. Seus resultados estão apresentados na Tabela 2. Uma estimativa do consumo energético que tornasse o processo economicamente vantajoso foi realizada, considerando-se a cotação do preço do cobre na Bolsa de Metais de Londres - LONDON METAL EXCHANGE [18], no dia 29 de janeiro de 2008, US\$ 7.170,00/ton, o valor do dólar comercial no mesmo dia, US\$ $1,00=\mathrm{R} \$ 1,779$, e o preço do $\mathrm{kWh}$ cobrado atualmente pela Light, $\mathrm{R} \$ 0,2013$, chegando-se ao resultado de $63,78 \mathrm{kWh} / \mathrm{kg}$ de cobre recuperado.

Tabela 2: Resultados do processo de eletrorrecuperação de cobre, para soluções contendo 0,2 mol/L de $\mathrm{K}_{2} \mathrm{SO}_{4}, 10^{-2} \mathrm{~mol} / \mathrm{L}$ de NaOH, $5 \times 10^{-3} \mathrm{~mol} / \mathrm{L}$ de $\mathrm{CN}^{-}$como NaCN e 3,15 x $10^{-3} \mathrm{~mol} / \mathrm{L}$ de Cu como CuCN, nas condições de vazão de $0,37 \mathrm{~mL} / \mathrm{s}$ e $50^{\circ} \mathrm{C}$.

\begin{tabular}{|c|c|c|c|c|c|c|}
\hline \multirow{8}{*}{$1 A$} & $\begin{array}{c}\text { Tempo } \\
\text { (h) }\end{array}$ & $\begin{array}{c}\text { Tensão cél. } \\
\text { (V) }\end{array}$ & $\begin{array}{c}\text { Eficiência de } \\
\text { corrente após } \\
\text { 3h (\%) }\end{array}$ & $\begin{array}{c}\text { Consumo } \\
\text { energético esp. } \\
\text { após } 3 \mathbf{h} \\
(\mathbf{k W h} / \mathbf{k g})\end{array}$ & $\begin{array}{c}\text { Concentração } \\
\text { de cobre (mg/L) }\end{array}$ & $\begin{array}{l}\text { Conc. } \\
\text { final } \\
\text { de } \mathrm{CN}^{-} \\
(\mathrm{mg} / \mathrm{L})\end{array}$ \\
\hline & 0,0 & 2,03 & \multirow{7}{*}{1,00} & \multirow{7}{*}{66,68} & 203 & \multirow{7}{*}{0,08} \\
\hline & 0,5 & 2,41 & & & 174 & \\
\hline & 1,0 & 1,27 & & & 104 & \\
\hline & 1,5 & 1,38 & & & 80 & \\
\hline & 2,0 & 1,33 & & & 51 & \\
\hline & 2,5 & 1,31 & & & 28 & \\
\hline & 3,0 & 1,32 & & & 15 & \\
\hline \multirow{8}{*}{$1,5 A$} & $\begin{array}{c}\text { Tempo } \\
\text { (h) }\end{array}$ & $\begin{array}{c}\text { Tensão cél. } \\
\text { (V) }\end{array}$ & $\begin{array}{l}\text { Eficiência de } \\
\text { corrente (\%) }\end{array}$ & $\begin{array}{c}\text { Consumo } \\
\text { energético esp. } \\
(\mathbf{k W h} / \mathbf{k g})\end{array}$ & $\begin{array}{c}\text { Concentração } \\
\text { de cobre }(\mathrm{mg} / \mathrm{L})\end{array}$ & $\begin{array}{l}\text { Conc. } \\
\text { final } \\
\text { de CN } \\
(\mathrm{mg} / \mathrm{L})\end{array}$ \\
\hline & 0,0 & 2,15 & 0,00 & 0,00 & 201 & \multirow{7}{*}{0,08} \\
\hline & 0,5 & 2,47 & 2,19 & 44,42 & 162 & \\
\hline & 1,0 & 2,50 & 3,65 & 27,38 & 71 & \\
\hline & 1,5 & 2,48 & 3,34 & 30,34 & 23 & \\
\hline & 2,0 & 2,48 & 2,70 & 37,75 & 9 & \\
\hline & 2,5 & 2,45 & 2,24 & 45,63 & 2 & \\
\hline & 3,0 & 2,48 & 1,88 & 54,59 & 0,7 & \\
\hline \multirow{8}{*}{$2 A$} & $\begin{array}{c}\text { Tempo } \\
\text { (h) }\end{array}$ & $\begin{array}{c}\text { Tensão cél. } \\
\text { (V) }\end{array}$ & $\begin{array}{l}\text { Eficiência de } \\
\text { corrente (\%) }\end{array}$ & $\begin{array}{c}\text { Consumo } \\
\text { energético esp. } \\
(\mathbf{k W h} / \mathbf{k g})\end{array}$ & $\begin{array}{c}\text { Concentração } \\
\text { de cobre (mg/L) }\end{array}$ & $\begin{array}{l}\text { Conc. } \\
\text { final } \\
\text { de } \mathrm{CN}^{-} \\
(\mathrm{mg} / \mathrm{L})\end{array}$ \\
\hline & 0,0 & 2,32 & 0,00 & 0,00 & 201 & \multirow{7}{*}{0,08} \\
\hline & 0,5 & 2,54 & 1,98 & 51,70 & 154 & \\
\hline & 1,0 & 2,57 & 3,14 & 33,24 & 52 & \\
\hline & 1,5 & 2,58 & 2,60 & 40,58 & 16 & \\
\hline & 2,0 & 2,53 & 2,09 & 50,67 & 3 & \\
\hline & 2,5 & 2,49 & 1,69 & 62,53 & 0,7 & \\
\hline & 3,0 & 2,53 & 1,41 & 74,92 & $<0,5$ & \\
\hline
\end{tabular}

Os padrões de descarte estabelecidos pelo CONAMA foram alcançados para o cobre, com um consumo energético que torne o processo aplicável, levando-se em consideração o resultado obtido com a corrente de 1,5A e o preço desse metal. Além disso, praticamente todo o cianeto livre presente foi oxidado. Porém, o padrão de descarte de cianeto (cianeto total) não foi alcançado na maioria dos casos devido à existência de cobre residual complexado, ficando o teor de cianeto total um pouco acima do permitido pela legislação. Entretanto, deve ser ressaltado que, mesmo esses limites não tendo sido atingidos, o processo é vantajoso pela economia substancial de reagentes usados na degradação do cianeto e também pela eliminação de lamas metálicas tóxicas.

Observou-se a formação de óxidos de cobre no anodo em todos os testes citados acima. Com 1 A, tal depósito foi estimado em 115 mg após pesagem do catodo antes e após o processo de eletrorrecuperação na forma de um revestimento preto, que como foi mencionado funciona como um catalisador da reação de oxidação de cianeto livre $[4,5,12]$. Como neste caso a maior parte do cobre foi depositada no anodo, a 
eficiência de corrente e o consumo energético específico só foram calculados após as três horas de eletrólise. Nos outros dois casos, o depósito anódico foi estimado em $25 \mathrm{mg}$.

A Figura 8 mostra os aspectos da tela de aço inoxidável, antes e após o processo de eletrorrecuperação de cobre. O depósito apresentado pode ser removido, anodicamente, em uma solução de ácido sulfúrico, como apresenta a Figura 9. Observa-se que este metal pode ser totalmente extraído do substrato de aço inoxidável em potenciais superiores a $600 \mathrm{mV}$ vs. ECS, sem que haja corrosão do substrato, que só é iniciada em potenciais superiores a $950 \mathrm{mV}$ vs. ECS [19].

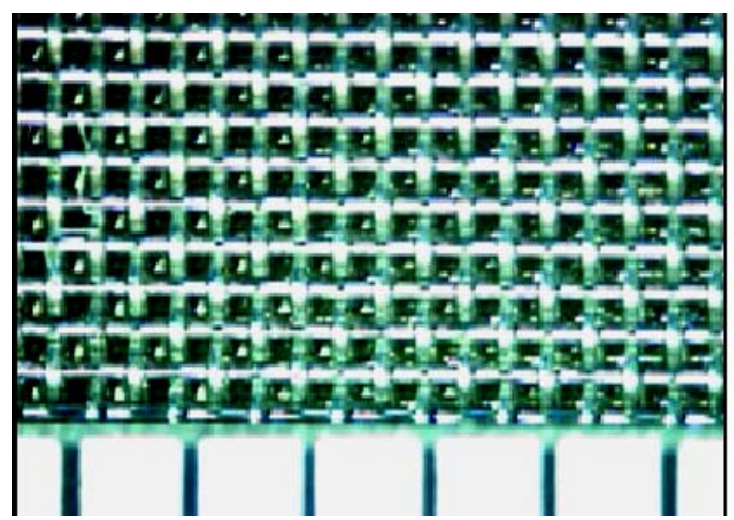

(A)

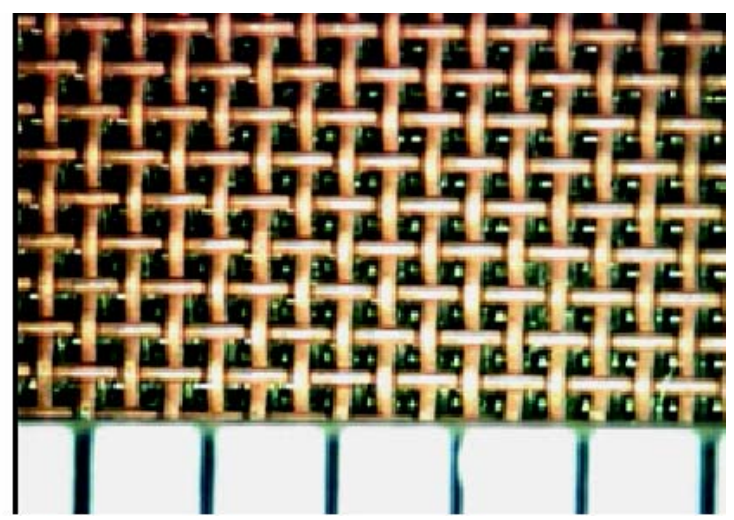

(B)

Figura 8: Aspectos da tela de aço inoxidável. (A) antes do processo de eletrorrecuperação de cobre e (B) após o referido processo.

Nota: escala em milímetros.

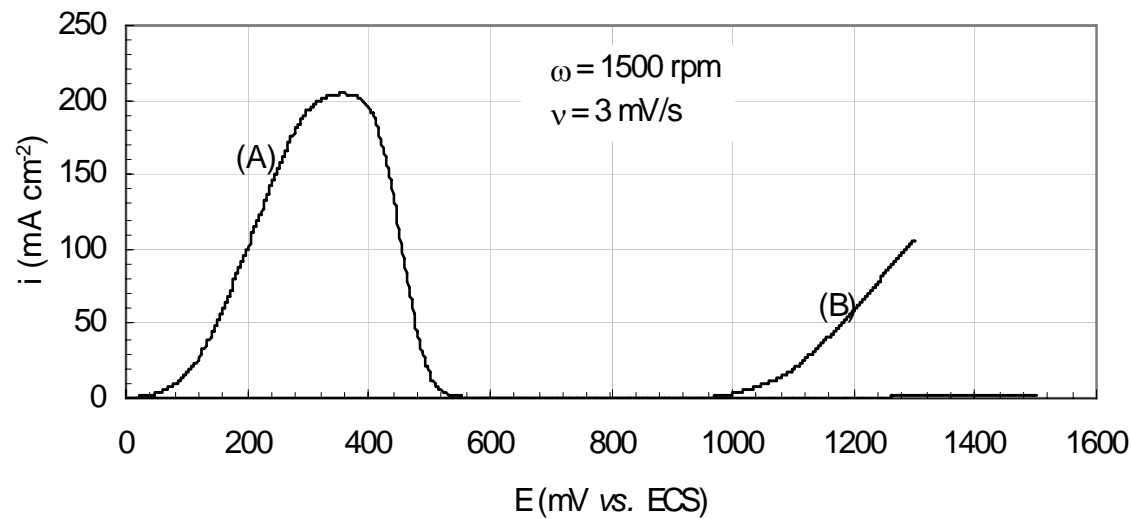

Figura 9: Voltametrias de varredura linear anódicas em solução molar de $\mathrm{CuSO}_{4}$, com 180g/L de $\mathrm{H}_{2} \mathrm{SO}_{4}$. Eletrodo de trabalho: aço inoxidável AISI 304. (A) com depósito de cobre eletrolítico e (B) sem o depósito [19].

\section{CONCLUSÕES}

O presente processo mostrou-se promissor para o tratamento de efluentes cianídricos diluídos, alcançando-se o padrão de descarte estipulado pelo CONAMA para o cobre e em alguns casos para o cianeto total com um consumo energético específico que tornasse o método vantajoso economicamente.

Testes em célula eletrolítica e voltamogramas mostraram a influência da vazão e da temperatura na eletrorrecuperação de cobre de soluções cianídricas diluídas. O aumento da vazão leva ao aumento da taxa de remoção de cobre, porém às custas do aumento do consumo energético do processo. E o aumento de temperatura resulta numa melhoria considerável da taxa de remoção de cobre devido ao deslocamento da predominância dos ciano-complexos de cobre em direção àqueles de menor número de coordenação, aumentando o potencial do par $\mathrm{Cu}(\mathrm{I}) / \mathrm{Cu}$.

Análise a partir da modelagem para um Reator de Fluxo Pistonado em batelada com reciclo comprovou que os processos eletroquímicos que ocorrem neste caso são controlados por transporte de massa, com valor de $\mathrm{k}_{\mathrm{m}}$ igual a $1,23 \times 10^{-5} \mathrm{~cm} / \mathrm{s}$. 
Os melhores resultados foram alcançados nas condições de vazão de $0,37 \mathrm{~mL} / \mathrm{s}$ e a $50^{\circ} \mathrm{C}$, chegandose a $0,7 \mathrm{mg} / \mathrm{L}$ de cobre e $0,08 \mathrm{mg} / \mathrm{L}$ de cianeto livre para uma corrente elétrica de $1,5 \mathrm{~A}$, e menor que 0,5 $\mathrm{mg} / \mathrm{L}$ de cobre e $0,08 \mathrm{mg} / \mathrm{L}$ de cianeto livre para uma corrente elétrica de $2 \mathrm{~A}$, após três horas de eletrólise.

Como os processos eletrolíticos propiciam a recuperação do metal na forma pura, o depósito obtido pode vir a ser uma fonte de renda ou de reciclagem interna, nos próprios banhos de eletrodeposição. Verificou-se que tal depósito pode ser facilmente removido, anodicamente, numa solução de ácido sulfúrico.

\section{AGRADECIMENTOS}

Ao CNPq e à CAPES pelos auxílios financeiros concedidos para o presente trabalho.

\section{BIBLIOGRAFIA}

[1] LU, J., DREISINGER, D.B., COOPER, W.C., “Thermodynamics of the aqueous copper-cyanide system”, Hydrometallurgy, v. 66, pp. 23-36, 2002a.

[2] HUNSOM, M., PRUKSATHORN, K., DAMRONGLERD, S., VERGNES, H., DUVERNEUIL, P., "Electrochemical treatment of heavy metals $\left(\mathrm{Cu}^{2+}, \mathrm{Cr}^{+6}, \mathrm{Ni}^{2+}\right)$ from industrial effluent and modeling of copper reduction”, Water Research, v. 39, pp. 610-616, 2005.

[3] MANAHAN, S.E., Fundamentals of Environmental Chemistry, Michigan, Lewis Publishers, 1993.

[4] SZPYRKOWICK, L., KELSALL, G.H., SOUTO, R.M., RICCI, F., KAUL, S.N., "Hydrodynamic effects on the performance of an electrochemical reactor for destruction of copper cyanide - Part I: in situ formation of the electro catalytic film”, Chemical Engineering Science, v. 60, pp. 523-533, 2005a.

[5] SZPYRKOWICK, L., KELSALL, G.H., SOUTO, R.M., RICCI, F., KAUL, S.N., "Hydrodynamic effects on the performance of an electrochemical reactor for destruction of copper cyanide - Part 2: reactor kinetics and current efficiencies”, Chemical Engineering Science, v. 60, pp. 535-543, 2005b.

[6] LU, J., DREISINGER, D.B., COOPER, W.C., "Copper electro winning from dilute cyanide solution in a membrane cell using graphite felt”, Hydrometallurgy, v. 64, pp. 1-11, 2002b.

[7] National Metal Finishing Resource Center, http://www.nmfrc.org Acessado em: 12/07/2006.

[8] ABNT - Associação Brasileira de Normas Técnicas, Norma ABNT NBR 10004:2004, Rio de Janeiro, ABNT, 2004.

[9] PALMER et al, “Metal/cyanide-containing wastes; Treatment Technologies”, Journal of Hazardous Materials, v. 24, pp. 96-100, 1990.

[10] DUTRA, A.J.B. et al, "O processo eletrolítico como alternativa para o tratamento de efluentes cianídricos”, REM - Revista Escola de Minas, v. 55, n. 4, pp. 267-272, 2002.

[11] HAMID, N.H.A., IDRIS, A., “Towards a sludge less heavy metal finishing industry for a cleaner environment”, Desalination, v. 106, pp. 411-413, 1996.

[12] CHENG, S.C., GATTREL, M., GUENA, T., MACDOUGALL, B., "The electrochemical oxidation of alkaline copper cyanide solutions”, Electrochimica Acta, v. 47, pp. 3245-3256, 2002.

[13] LEMOS, F.A., SOBRAL, L.G., DUTRA, A.J.B., “Copper electro winning from gold plant waste streams”, Minerals Engineering, v. 19, pp. 388-398, 2006.

[14] STAVART, A., LEROY, C., VAN LIERDE, A., "Potential use of carbon felt in gold hydrometallurgy", Minerals Engineering, v. 12, n. 12, pp. 545-558, 1999.

[15] REYES-CRUZ, V., GONZÁLEZ, I., OROPEZA, M.T., "Electro-recovery of gold and silver from a leaching solution using a three-dimensional reactor”, Electrochimica Acta, v. 49, pp. 4417-4423, 2004. 
[16] PLETCHER, D., WALSH, F.C., Industrial Electrochemistry, 2 ed., Londres, Chapman and Hall, 1990.

[17] WALSH, F.C., READE, G.W., "Electrochemical techniques for the treatment of dilute metal-ion solutions”, In: C.A.C Sequeira, Environmental Oriented Electrochemistry, Elsevier, pp. 3-44, 1994.

[18] LONDON METALS EXCHANGE, http://www.lme.co.uk. Acessado em: 29/01/2008.

[19] DUTRA, A.J.B., ROCHA, G.P., POMBO, F.R., "Recuperação de cobre eletrolítico a partir de solução gasta de cubas de eletrodeposição em meio cianídrico”, Revista Matéria, v. 12, n. 1, pp. 237 - 244, 2007. 